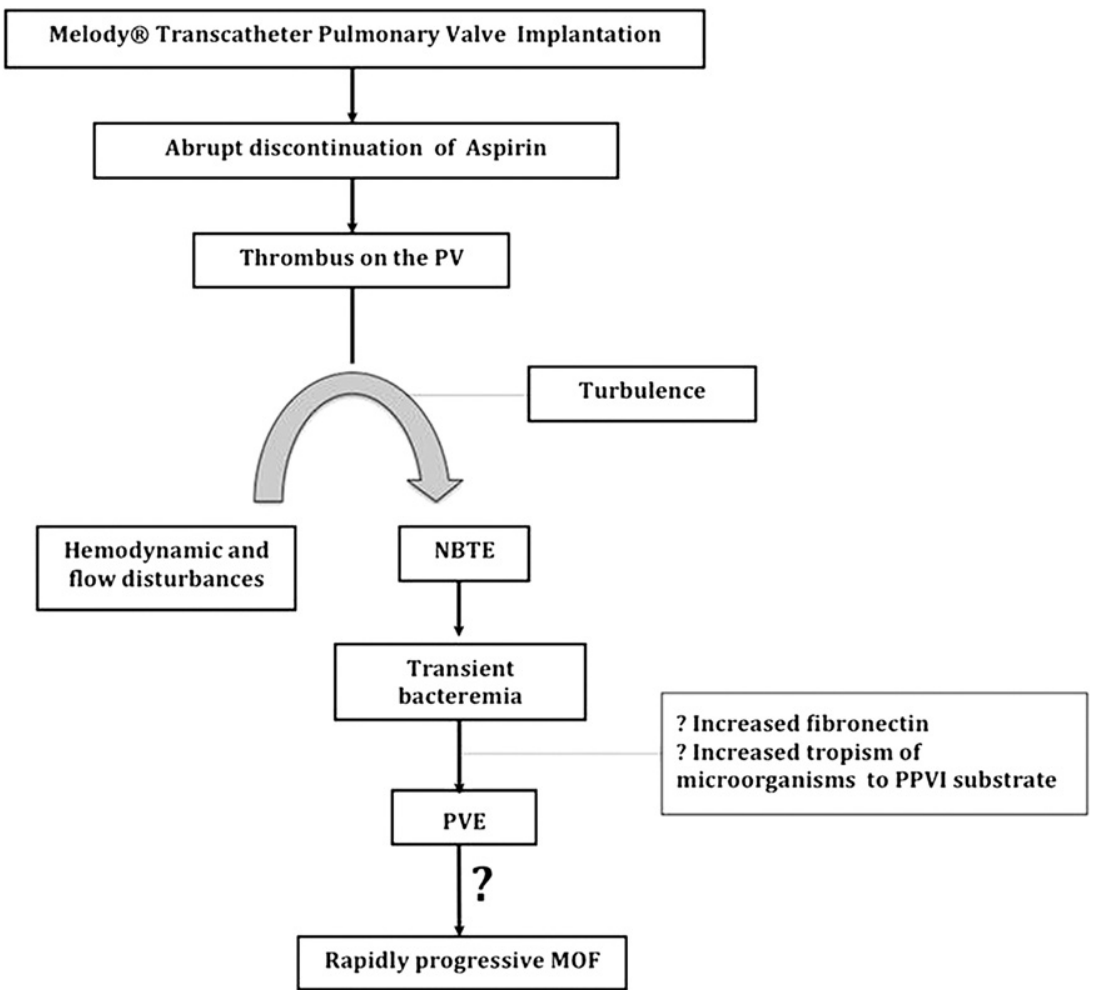

FIGURE 4. Proposed pathophysiologic mechanism for infective endocarditis of the Melody valve. $P V$, Pulmonary valve; $N B T E$, nonbacterial thrombotic endocarditis; $P P V I$, percutaneous pulmonary valve insertion; $P V E$, prosthetic valve endocarditis; $M O F$, multiorgan failure.

\section{References}

1. Lurz P, Coats L, Khambadkone S, Nordmeyer J, Boudjemline Y, Schievano S, et al. Percutaneous pulmonary valve implantation: impact of evolving technology and learning curve on clinical outcome. Circulation. 2008;117: 1964-72.

2. Lurz P, Bonhoeffer P, Taylor AM. Percutaneous pulmonary valve implantation: an update. Expert Rev Cardiovasc Ther. 2009;7:823-33.
3. Atamanyuk I, Raja SG, Kostolny M. Bartonella henselae endocarditis of percutaneously implanted pulmonary valve: a case report. J Heart Valve Dis. 2011;20:94-7.

4. Boudjemline Y, Bonnet D, Massih TA, Agnoletti G, Iserin F, Jaubert F, et al. Use of bovine jugular vein to reconstruct the right ventricular outflow tract: early results. J Thorac Cardiovasc Surg. 2003;126:490-7.

5. Bajraktari G, Olloni R, Daullxhiu I, Ademaj F, Vela Z, Pajaziti M. MRSA endocarditis of bovine Contegra valved conduit: a case report. Cases J. 2009;2:57.

\title{
Iatrogenic left internal thoracic artery to left subclavian vein fistula after excimer laser pacemaker lead extraction
}

\author{
Melissa M. Anastacio, MD, ${ }^{\mathrm{a}}$ Mario Castillo-Sang, MD, ${ }^{\mathrm{a}}$ Timothy W. Smith, MD, DPhil, ${ }^{\mathrm{b}}$ \\ Nael Saad, MD, ${ }^{\mathrm{c}}$ and Jennifer S. Lawton, MD, ${ }^{\mathrm{a}}$ St Louis, Mo
}

\footnotetext{
From the Division of Cardiothoracic Surgery, ${ }^{\mathrm{a}}$ Department of Surgery, the Division of Cardiovascular Medicine, ${ }^{\mathrm{b}}$ Department of Medicine, and the Mallinckrodt Institute of Radiology, ${ }^{\mathrm{c}}$ Washington University School of Medicine, St Louis, Mo.

Disclosures: Authors have nothing to disclose with regard to commercial support.

Received for publication Dec 15, 2011; accepted for publication Jan 4, 2012; available ahead of print Feb 3, 2011.

Address for reprints: Jennifer S. Lawton, MD, Washington University School of Medicine, 660 S Euclid Ave, Campus Box 8234, St Louis, MO 63110 (E-mail: lawtonj@wustl.edu).

J Thorac Cardiovasc Surg 2012;143:e35-7

$0022-5223 / \$ 36.00$

Copyright (c) 2012 by The American Association for Thoracic Surgery

doi:10.1016/j.jtcvs.2012.01.014
}

Percutaneous methods of pacemaker and defibrillator lead extraction have decreased the morbidity associated with pacemaker management through traditional open chest surgery but carry their own serious complications, including bleeding, cardiovascular injury, hemothorax or pneumothorax, and even death. We report here a rare case of iatrogenic arteriovenous fistula formation after percutaneous pacemaker lead extraction with an excimer laser. 


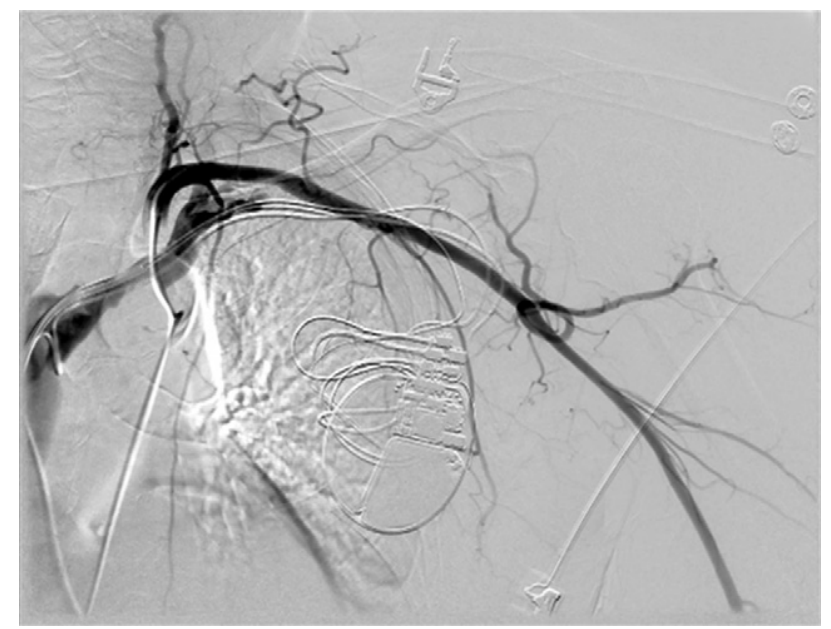

FIGURE 1. Arteriogram showing fistula between left internal thoracic artery and left subclavian vein.

\section{CLINICAL SUMMARY}

A 70-year-old man with complete heart block, atrial fibrillation, sick sinus syndrome, and a dual-chamber pacemaker underwent lead extraction to allow implantation of a new biventricular pacemaker-defibrillator. The patient was pacemaker dependent and had an ejection fraction of $28 \%$. The original 2-lead pacemaker had been placed 18 years previously, and 2 additional leads had been added since. A 14F excimer laser sheath (Spectranetics Corporation, Colorado Springs, Colo) was used because the leads could not be removed by traction with locking stylets. The procedure was difficult as a result of extensive adhesions within the vein and of overcrowding. High venous pressure resulted in a large amount of blood loss. One atrial and both right ventricular leads were removed, and a new right ventricular automatic implantable cardioverter defibrillator lead and left ventricular lead were placed. The patient received 2 units of blood during the operation and remained in hemodynamically stable condition. He was found to have a new murmur on clinical examination but was otherwise free of symptoms.

A computed tomographic scan with intravenous contrast was suggestive of but not diagnostic for an arteriovenous fistula. Arteriography (Figure 1) revealed an arteriovenous fistula between the left internal thoracic artery and the left subclavian vein. The patient underwent successful coiling of the left internal thoracic artery by interventional radiology (Figure 2) and was subsequently discharged home without further complications.

\section{DISCUSSION}

Percutaneous methods of pacemaker and defibrillator lead extraction have decreased the complexity and morbidity associated with traditional open chest surgery. These

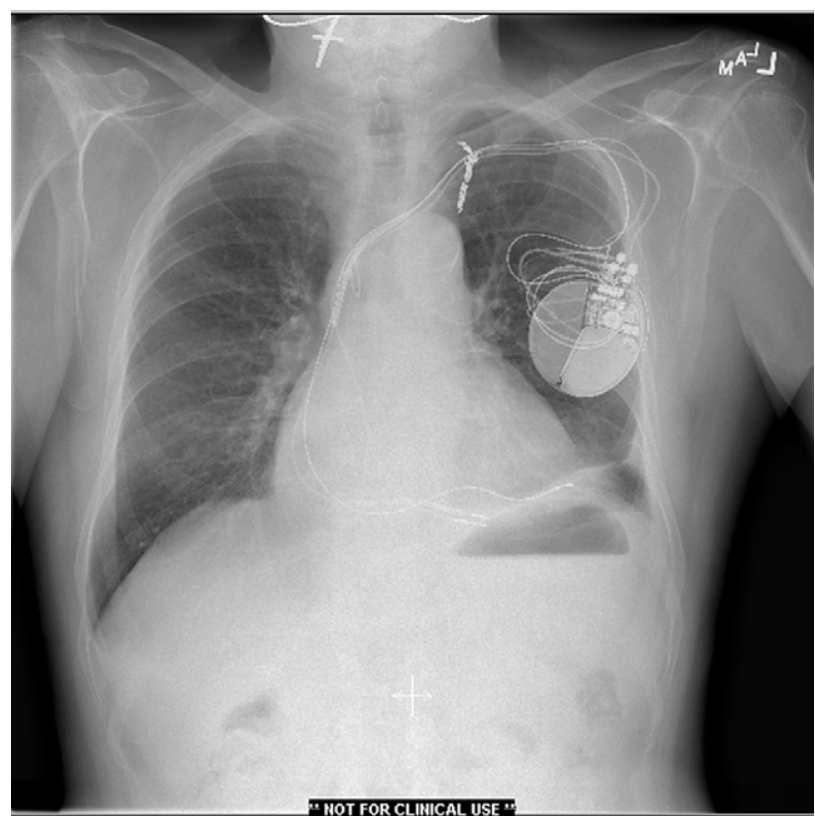

FIGURE 2. Postprocedure chest radiograph shows lead wires and coils within the left internal thoracic artery.

methods, however, can be fraught with their own serious complications, including bleeding requiring transfusion, cardiac or vascular injury, hemothorax or pneumothorax, and death. Most of these injuries involve direct cardiac or great vessel injury, often requiring sternotomy. A much less frequent but equally serious complication is iatrogenic arteriovenous fistula formation.

Iatrogenic arteriovenous fistula formation associated with excimer laser-assisted lead extraction has only been documented in isolated case reports. The first case was reported in $1999 .{ }^{1}$ Since then, 6 other cases have been reported in the literature, including 2 from our institution. ${ }^{2-5}$ Clinical presentations have included a combination of symptoms (acute-onset severe chest pain or progressive dyspnea and extremity edema), signs (hemodynamic instability, new murmur or thrill), and radiographic abnormalities (widened mediastinum, unilateral hemothorax, valvular dysfunction). Diagnosis has been confirmed with formal angiography. All but 1 reported case involved pacemaker wires. Primary reported indications for extraction have been lead malfunction or replacement and infection. In most of the reported cases, brisk or bright red bleeding was noted at the puncture site or in the sheath. After diagnosis, 1 patient was managed expectantly, 3 underwent endovascular procedures ( 2 stent grafts, 1 coil embolization), and 2 required operative intervention. Among the 7 cases documented, there was 1 fatality.

Such injuries can result from lead overcrowding, adhesion formation, and technical factors. Long-term presence of pacing or defibrillator leads causes an inflammatory 
reaction within the vein that results in adhesion formation. The proximity of great vessels allows scarring between adjacent artery and vein. Laser extraction in thin-walled veins may involve removal or tearing of the venous wall, thus creating a communication with the adjacent artery.

\section{CONCLUSIONS}

Laser-assisted lead extraction has significantly improved the success and efficiency of lead removal. Arteriovenous fistula formation is a rare but potentially catastrophic complication. Success with endovascular techniques has provided an effective and less invasive management option. These cases stress the importance of judicious application of extraction guidelines, meticulous technique, and prompt diagnosis and management of these potentially catastrophic complications.

\section{References}

1. Bracke FA, van Gelder B, Meijer A. Arteriovenous fistula after injury of the left Internal mammary artery during extraction of pacemaker leads with a laser sheath. Pacing Clin Electrophysiol. 1999;2:833-4.

2. Kumins NH, Tober JC, Love CJ, Culbertson TA, Gerhardt MA, Irwin RJ, et al. Arteriovenous fistulae complicating cardiac pacemaker lead extraction: recognition, evaluation, and management. J Vasc Surg. 2000;32:1225-8.

3. Milla F, Mack CA, Girardi LN. Arteriovenous fistula after laser-assisted pacemaker lead extraction. Ann Thorac Surg. 2006;81:2304-6.

4. Lawton JS, Moon MR, Curci JA, Rubin BG, Smith TW, Gleva MJ, et al. Management of arterial injuries caused by laser extraction of indwelling venous pacemaker and defibrillator leads. Pacing Clin Electrophysiol. 2006;29:917-20.

5. O'Connor DJ, Gross J, King B, Suggs WD, Gargiulo NJ 3rd, Lipsitz EC. Endovascular management of multiple arteriovenous fistulae following failed laserassisted pacemaker lead extraction. J Vasc Surg. 2010;51:1517-20.

\section{HeartWare continuous-flow ventricular assist device thrombosis: The Bad Oeynhausen experience}

Nadia Aissaoui, MD, Jochen Börgermann, MD, PhD, Jan Gummert, MD, PhD, and Michiel Morshuis, MD, Bad Oeynhausen, Germany

The HeartWare (HeartWare International, Inc, Framingham, Mass), ventricular assist device (VAD) is a small, third-generation, implantable continuous-flow VAD. ${ }^{1}$ Despite this system's advantages, the rates of thrombus formation and thromboembolic events are not negligible and can reach $8 \%{ }^{1}$

Pump thrombus requires emergency treatment to restore an adequate flow and to avoid life-threatening complications. The therapeutic options are few: thrombolytic therapy, either systemic or local, ${ }^{2,3}$ with the accompanying risks of recurrence and bleeding, and surgical device exchange, which is associated with the problems typical of an urgent reoperative procedure. ${ }^{4}$

There are currently no specific recommendations concerning the management of pump thrombosis. This report

\footnotetext{
From the Heart \& Diabetes Center North Rhine-Westphalia, Bad Oeynhausen, Germany.

Disclosures: Authors have nothing to disclose with regard to commercial support. HeartWare is manufactured by HeartWare International, Inc, Framingham, Mass.

Received for publication Dec 5, 2011; accepted for publication Dec 14, 2011; available ahead of print Jan 16, 2012.

Address for reprints: Nadia Aissaoui, MD, Department of Thoracic and Cardiovascular Surgery, Heart \& Diabetes Center North Rhine-Westphalia, Georgstrasse 11, 32545 Bad Oeynhausen, Germany (E-mail: nadia.aissaoui@sat.aphp.fr).

J Thorac Cardiovasc Surg 2012;143:e37-9

$0022-5223 / \$ 36.00$

Copyright (c) 2012 by The American Association for Thoracic Surgery

doi:10.1016/j.jtcvs.2011.12.035
}

aims to summarize the Bad Oeynhausen experience with the management of HeartWare VAD thrombus.

\section{CLINICAL SUMMARY \\ Patients}

Between August 2009 and May 2011, 98 patients received HeartWare VADs (88 left VADs and 10 biventricular VADs) in Bad Oeynhausen, Germany. Six patients showed development of clinical signs of pump thrombosis associated with device malfunction. One patient had pump thrombosis develop on 2 separate occasions (within 6 months of each other) as a result of noncompliance with the anticoagulation regimen.

\section{Diagnosis of Device Thrombosis}

The diagnosis of thrombosis was most often made by indirect evidence. Clinical suspicion was raised in the cases of patients 1,2,3, and 4 because of documented subtherapeutic international normalized ratio values (patient 3 ), history of a transitory ischemic attack (patient 1 ), or icterus and dark urine on examination (patients 1, 2, 3, and 4). Pump checks revealed in all patients an increase of power consumption plus abnormally increased flow values differing from baseline. Laboratory tests always showed high lactate dehydrogenase and free hemoglobin levels. Demographic data are summarized in Table 1. 